\title{
Uma Reflexão sobre o papel do Design e a Ética no Consumo
}

Yuri Simon da Silveira;

Daniel de Lima Veloso;

Julia Santiago Salles

\section{resumo:}

Esse artigo procura fazer uma reflexão sobre o consumo e o consumismo, e o papel do design, e suas competências, como possível colaborador na busca de modelos sustentáveis e éticos de consumo. Analisando a prática do consumo por meio do estudo das necessidades primárias e secundárias do consumidor, como também o papel da indústria e sua relação com a publicidade e o marketing.

palavras-chave:

ética; consumo; design; marketing; necessidades 


\section{Design: significações e atribuições}

A palavra design assume vários sentidos na língua portuguesa. Ao longo do tempo o termo se disseminou sendo apropriado por diversas áreas. Não é incomum identificarmos seu uso popular apenas como uma característica estética de algum objeto, como um sinônimo de requinte e beleza em ambientes ou produtos consumidos, uma atribuição que favoreça o consumo de determinado objeto pela sociedade. Mas o lugar do design na sociedade vai muito além de simplesmente imprimir características estéticas e perceptivas a um determinado projeto. Porem, não se pode julgar de forma negativa, sem uma reflexão, essa utilização popular do termo, uma vez que, até mesmo alguns designers, ainda hoje, tem dificuldade de identificar as próprias competências da profissão, e muitos desconhecem ao certo qual a melhor definição para a palavra design.

Segundo Flusser (2013) pode-se entender design a partir de uma série de significações, pois em inglês, a palavra funciona tanto se aplicada como substantivo, onde pode significar entre outras coisas: propósito, plano, intenção, meta, forma, estrutura básica; como também se aplicada como verbo, onde "to design - significa, entre outras coisas, tramar algo, simular, projetar, esquematizar, configurar, proceder de modo estratégico" (FLUSSER, 2013, p. 181). Essas significações para o design poderão também ser observadas nas competências apresentadas pela entidade representativa para o profissional do design, o The World Design Organization (WDO) ${ }^{1}$ por meio da Sociedade de Designers Industriais da América (IDSA) ${ }^{2}$.

A definição de design, suas atribuições e competências é o ponto de partida para identificarmos uma estreita ligação existente entre o design e o consumo, atendo-se a importantes aspectos desta definição: os focos estabelecidos entre o projeto de design e o usuário/consumidor, o mercado e a indústria. Pode-se assim estabelecer uma reflexão sobre as questões éticas relacionadas ao consumo e ao papel que compete ao designer nesse sistema. Ao se refletir sobre a sociedade de consumo, tendo como entendimento aquele consumidor que busca possuir para pertencer, ou aquele que possui algo em busca de satisfação, se requer um desafio que rompe com tradições ideológicas e provoca inúmeras inquietações filosóficas acerca do ritmo consumista frenético e da construção e validade do pensamento lógico do consumidor regulado pelas ambições do mercado.

\subsection{Competências}

Na $29^{\text {a }}$ Assembleia Geral do ICSID - Council of Societies of Industrial Design, denominação pela qual era conhecida a Organização Mundial de Design (WDO), realizada em outubro de 2015 em Gwangju na Coréia do Sul, o Comitê de Prática Profissional revelou uma definição renovada e estendida para o design na sociedade contemporânea.

Desenho Industrial é um processo estratégico de solução de problemas que impulsiona a inovação, constrói o sucesso do negócio e leva a uma melhor qualidade de vida por meio de produtos, sistemas, serviços e experiências inovadores. O Desenho Industrial preenche a lacuna entre o que é e o que é possível. É uma profissão transdisciplinar que utiliza a criatividade para resolver problemas e cocriar soluções com o intuito de tornar um produto, sistema, serviço, experiência ou negócio melhor. Em sua essência, o Desenho Industrial oferece uma maneira mais otimista de olhar para o futuro, reenquadrando os problemas como oportunidades. Liga a inovação, tecnologia, pesquisa, negócios e clientes para fornecer um novo valor e vantagem competitiva nas esferas econômica, social e ambiental. (ICSID, 2015, tradução do autor)

\footnotetext{
${ }^{1}$ WDO (The World Design Organization) é uma organização não governamental para proteção e promoção dos interesses da profissão do Design Industrial. Disponivel em: <https://wdo.org/about/definition/> Acesso em 08 de agosto de 2020

${ }^{2}$ Fundada em 1965, a Industrial Designers Society of America (IDSA) é uma organização sem fins lucrativos e uma das associações mais antigas e maiores de adesão para profissionais do design. Disponivel em: $<$ https://www.idsa.org/what-industrial-design> Acesso em 08 de agosto de 2020
} 
Essas competências são desenvolvidas e adquiridas tanto pela vivência em sua profissão, nos projetos desenvolvidos pelo profissional, na solução de problemas, como também a partir a formação acadêmica adquirida. Reforçando esse conceito de competências, a IDSA também estabelece um conceito de design fornecido pelo próprio campo.

Desenho Industrial (ID) é a prática profissional de projetar produtos, dispositivos, objetos e serviços usados por milhões de pessoas em todo o mundo todos os dias. Os designers industriais geralmente se concentram na aparência física, na funcionalidade e na capacidade de fabricação de um produto, embora estejam frequentemente envolvidos em muito mais durante um ciclo de desenvolvimento. Tudo isso, em última análise, se estende ao valor e experiência global duradouro que um produto ou serviço oferece aos usuários finais. Cada objeto com o qual você interage diariamente em sua casa, escritório, escola ou ambiente público é o resultado de um processo de design. Durante esse processo, inúmeras decisões são tomadas por um designer industrial (e sua equipe) que visam melhorar sua vida por meio de um design bem executado. (IDSA, 2020, tradução do autor)

Percebe-se que, embora a aparência física seja citada, as características de atividades ou competências são de caráter sistêmico, com foco na experiência global proporcionada ao usuário, e isso é estabelecido pelos dois órgãos representativos como premissa para o desenvolvimento de projetos em design, indo do objeto ao serviço.

\subsection{Porque Consumimos?}

Bauman (2008) afirma que o consumo faz parte de todas as formas de vida de maneira integral e permanente, tendo existido desde a origem dos seres vivos, com raízes muito antigas. Porém quando o consumo passa a ser uma ocupação e preocupação de todos os seres humanos enquanto indivíduos adquire o aspecto de consumismo, que pode ser considerado um atributo da sociedade atual, que consome excessivamente aquilo que não necessita em um excesso de aquilo de que se necessita, mas representa o excesso de aquisições que podem ser consideradas supérfluas ou desnecessárias.

Moderno (2000) ao questionar por que consumimos um produto afirma que as motivações para o consumo estão estreitamente vinculadas às necessidades que as pessoas podem ter em cada momento. Essas necessidades são muitas vezes confundidas com carências, desejos e vontades que geram um impulso para o consumo, que se encaixam muito mais em características secundárias das necessidades de consumo do que nas características primárias, entendendo que as necessidades primárias são aquelas relacionadas a questões fisiológicas e de segurança, como é apresentado na pirâmide de Maslow (figura 1).

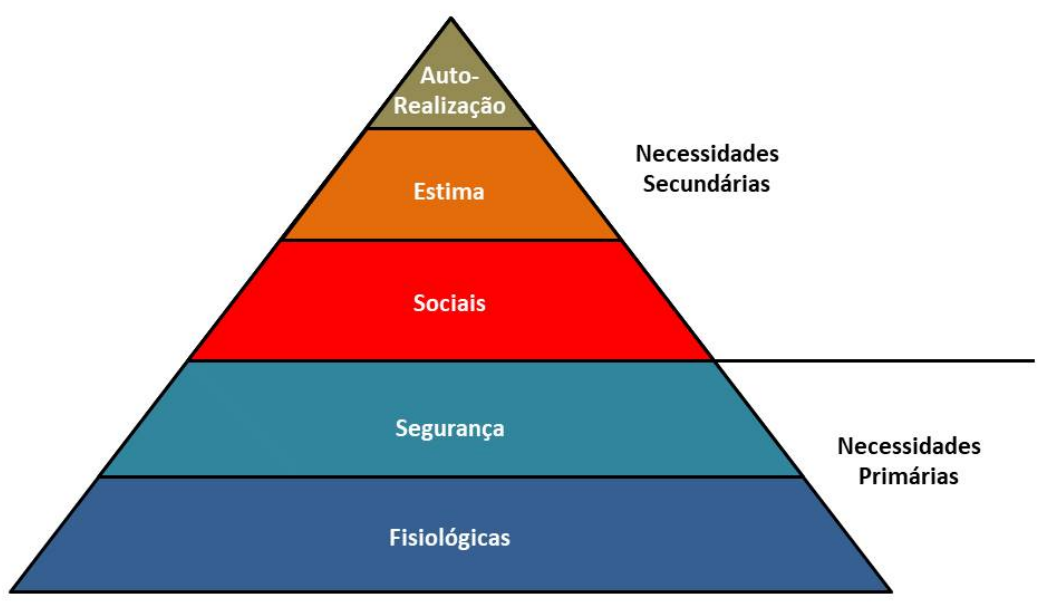

Figura 1 - Pirâmide de Maslow - Fonte: (Autor), 2020 - Arquivo pessoal 
Para cada necessidade existe ao menos uma motivação ou uma pluralidade de motivações diversas, como por exemplo: a necessidade de se possuir um automóvel, dela podem surgir motivações distintas para cada pessoa ou grupo social, com questionamentos diferentes de um indivíduo para o outro. Essas motivações são um conjunto de fatores que afetam o comportamento de uma pessoa, uma força que impulsiona o consumidor para o ato da compra. Comprar e trocar o objeto velho pelo novo aumenta a emoção na vida cotidiana. A necessidade de sentir novas sensações e estímulos pode servir de fator impulsionador da compra. Também para Moderno (2000) um grande passo para se compreender o comportamento de consumo a partir das necessidades vem do estudo apresentado pelo psicólogo estadunidense Abraham Maslow, que estabeleceu por ordem de importância, como uma pirâmide, cinco patamares de hierarquização das necessidades para o ser humano, que podem ser divididas em dois grandes conjuntos, primárias e secundárias: as necessidades primárias, em dois patamares, fisiológicas, e depois segurança e proteção; e as necessidades secundárias, em três patamares, sociais, ego e autorrealização. Por essa pirâmide percebe-se que, só se passa de um patamar para outro quando as necessidades correspondentes a aquele anterior forem supridas. Bauman (2008) apresenta uma reflexão sobre consumismo e sua relação com desejos e vontades.

Pode-se dizer que consumismo é um tipo de arranjo social resultante da reciclagem de vontades, desejos e anseios humanos rotineiros, permanentes e, por assim dizer, "neutros quanto ao regime", transformando-os na principal força propulsora e operativa da sociedade, uma força que coordena a reprodução sistêmica, a integração e a estratificação sociais, além da formação de indivíduos humanos, desempenhando ao mesmo tempo um papel importante nos processos de auto identificação individual e de grupo, assim como na seleção e execução de políticas de vida individuais. (BAUMAN, 2008, p. 41)

Bauman (2008) reflete ainda que, o consumidor de hoje para manter a autoestima, é estimulado por um bombardeio de informações de que é indispensável adquirir determinados produtos como forma pertencerem a uma desejada posição social. Vemos uma inversão, onde agora a economia trabalha para desenvolver um desejo e não mais suprir o desejo existente. A promessa de uma sensação nova, diferente, da satisfação dos desejos que ainda nem haviam sido percebidos, estimula o consumidor a querer mais do que a própria satisfação de consumir o prometido. Embora de acordo com Amorim (2010) não podemos ignorar a importância do design nesse processo. Pois a autora reconhece o fato do designer mediar à produção e o consumo além da produção e uso, estando intrinsicamente ligado ao conceito capitalista contemporâneo de produção e sendo contratado para produzir produtos que satisfaçam desejos e necessidades, estimulando a venda e aumentando o lucro das empresas.

Condenar o consumo de produtos de prestígio, portanto, é ignorar um modo de se relacionar com o design que interage com os níveis visceral, comportamental e reflexivo de forma bastante peculiar. Demandando, geralmente, beleza, qualidade, exclusividade e distinção em doses especiais. (AMORIM, 2010, p. 8)

Norman (2008) também argumenta que o lado emocional do design, essa relação mais visceral com os objetos que consumimos, pode ser um dos elementos mais importantes para o sucesso de um produto, um dos fatores para que seja consumido, em relação aos elementos práticos que ele transmite, já que segundo o autor as pessoas tem a percepção de que conseguem produzir melhor quando estão cercadas por objetos esteticamente prazerosos, e segundo Löbach (2001), a função estética está presente na relação entre usuário-produto, no que se diz respeito aos processos sensoriais, "[...] a função estética dos produtos é um aspecto psicológico da percepção sensorial durante o seu uso" (LÖBACH, 2001, p.39), portanto essa sensação pode não ser a mesma para todos os usuários, já que cada usuário pode ter uma experiência diferente segundo suas necessidades em relação ao objeto, desde o prazer eficiente da função para o qual o objeto foi projeto, até mesmo a sensação de posse de um objeto diferenciado esteticamente estimulando as sua comercialização e o desejo de consumo. No entanto, de acordo com Amorim "esse sistema produtivo orientado pela beleza em função do estímulo 
às vendas contribui para que o design termine sendo confundido com sua própria dimensão estética, configurando-se aí uma grave imprecisão" (AMORIM, 2010, p. 6).

Ainda de acordo com Norman (2008) a grande maioria das pessoas possui objetos que não custaram preços elevados, são objetos que significam mais que a sua mera posse, pois esses objetos possuem um valor de estima, estima essa que pode ter sido atribuída ao objeto por questões particulares como herança de família, um presente de alguém considerada importante, ou pelo desejo de posse por algo que faça com que a pessoa se recorde de bons momentos, podendo ainda atribuir ao objeto um valor que represente a projeção de futuro da pessoa. Baxter (2001) esclarece que todos nós temos uma autoimagem, baseada nos valores pessoais e sociais que possuímos. Faz parte de a natureza humana nos cercarmos de objetos que reflitam a nossa autoimagem. Esse pensamento é também compartilhado por

\subsection{Sociedade de Consumo - Consumismo}

O consumo está diretamente ligado à revolução industrial e ao capitalismo como esclarece Olívio (2010). A sociedade se moldou em uma sociedade de consumo graças a estratégias capitalistas que estão gerando sérias consequências para o planeta, já que o nível de consumo, segundo o autor, é simplesmente insustentável.

A cultura do consumo se originou a partir da Revolução Industrial e se consolidou durante a Segunda Guerra Mundial, com o nascimento da sociedade de consumo americana. Também surgiram neste período conceitos como "obsolescência planejada", "marketing" e "produtos descartáveis", que deram novos formatos às relações de consumo, fixando o consumismo como entidade capitalista. (OLÍVIO, 2010, p.16).

O documentário "Comprar, tirar, comprar" da roteirista e cineasta espanhola Cosima Dannoritzer, questiona porque apesar dos avanços tecnológicos, os produtos de consumo duram cada vez menos, e por meio da narrativa e de imagens conta a história da obsolescência programada ${ }^{3}$, nome dado à vida curta de um bem, objeto ou produto intencionalmente projetado de forma que sua durabilidade ou funcionamento se dê apenas por um período reduzido. Baterias que diminuem significativamente seu desempenho após 18 meses de serem estreadas, chegando a parar de funcionar, impressoras que bloqueiam as impressões quando estes chegam a um número determinado e lâmpadas que se fundem ou se queimam após chegar a mil horas de uso, uma forma de estimular o consumo por meio da troca de um produto que teve sua vida útil reduzida por um novo que promete melhor rendimento de produtividade.

Essa característica adotada pela indústria contradiz o pensamento de Manzini e Vezzoli (2005) onde afirmam que, o desenvolvimento de produtos mais duráveis que promovam mudanças comportamentais da sociedade é uma premissa dos projetos de design, incentivando o menor consumo e descarte de objetos, portanto pode-se entender que a sustentabilidade é um dos grandes desafios de nosso tempo. É necessário viver em ambientes sociais onde nossos desejos e necessidades possam ser atendidas sem comprometer as possibilidades das gerações futuras em satisfazer suas necessidades.

Segundo Bauman (1999) para saciar seus desejos o indivíduo tende a consumir, portanto novos desejos e anseios da sociedade de consumo precisam ser gerados, desta forma a indústria pode preencher esses anseios com novos produtos existentes nas prateleiras. "[...] principal força propulsora e operativa da sociedade" (BAUMAN, 2008, p. 41). A principal reflexão nesse processo ou ciclo é que esses desejos não podem nunca serem saciados completamente, pois o sujeito totalmente satisfeito tende a não necessitar e, portanto não desejar, já o sujeito insatisfeito fica mais exposto à possibilidade de novas aquisições, descartando antigos produtos que já foram considerados ideais em um momento

\footnotetext{
${ }^{3}$ Comprar, tirar, comprar: la história secreta de la obsolescencia programada. É um documentário da diretora espanhola Cosima Dannoritzer e produzido pela RTVE.es sobre a redução deliberada da vida útil de um produto para incrementar seu consumo. Disponível em: $<$ https://www.youtube.com/watch? $\mathrm{v}=$ SoAO-tOHLNg $>$ Acesso em 08 de agosto de 2020
} 
do passado, tomando-os obsoletos de uma forma rápida, e por isso, objetos descartáveis. Pode-se observar na sociedade atual a existência de uma grande ânsia do indivíduo para se afirmar em um estilo de vida, que além de instituir critérios de comportamento cria ainda uma situação de autoanalise e autojulgamento. O consumismo então trabalha a ideia de ilusão identitária, com todos os fetiches, onde o consumidor ao adquirir um produto aparenta estar mais alegres e realizado. Desse comportamento, induzido pela indústria e imposto pelo estilo consumista da sociedade contemporânea, surge uma grande demanda de compra e descarte de produtos que é indispensável para atingir o estilo de vida desejado.

É importante então refletir sobre a origem desse ciclo de consumo e descarte. Para Tavares (2014) a propaganda aderida ao produto é um mecanismo extremamente poderoso para transferência de significados, a ponto de poder atribuir qualquer significado a qualquer produto. O consumidor deve ser atacado por promessas, ofertas e informações o tempo todo. Ter muitas possibilidades traz uma grande incerteza na escolha e isso o leva a várias tentativas e erros. Em grande parte das vezes, esse meio gera uma sensação de angustia e deslocamento dando origem a uma crise de identidade, onde a multiplicidade transforma o ser em alguém perdido, inseguro e depressivo, sem a vontade de conhecer-se e encontrar-se. Em conjunto com o marketing e a publicidade, o design pode corroborar com um modelo de vida insustentável que precisa ser repensado de forma urgente. Para Moderno (2010) A publicidade por meio da comunicação desperta mecanismos que conduzem as pessoas a um comportamento desejado.

A comunicação publicitária tem duas componentes principais: por um lado, está a componente de carácter informativo, que trata de informar, de dar a conhecer algo sobre o objeto do anúncio; por outro lado, está a componente persuasiva, que, de uma forma mais clara, trata deliberadamente de exercer influência nas pessoas. Ambos aspectos, o informativo e o persuasivo, estão estreitamente unidos na intencionalidade da própria publicidade. (MODERNO, 2010, p.1)

Ainda de acordo com Olívio (2010) com o marketing transformado em referência para o consumismo, os valores sociais tem sofrido uma contínua e intensa deturpação, tornando tudo como parte do mercado e não apenas uma ferramenta de inserção da empresa na sociedade. Com isso a indústria da publicidade sob a chancela do marketing se preocupa menos com consumo equilibrado e se posiciona com muito mais devoção a cultura do consumismo e aos interesses de lucro dos fabricantes.

Para aumentar sua capacidade de consumo, os consumidores não devem nunca ter descanso. Precisam ser mantidos acordados e em alerta sempre, continuamente expostos a novas tentações, num estado de excitação incessante - e também, com efeito, em estado de perpétua suspeita e pronta insatisfação. (BAUMAN, 1998, p. 9293)

Alves (2015) parte da premissa de que a própria existência do sistema de produção capitalista é baseada na produção e no consumo crescente como forma de gerar retorno financeiro a indústria e ao mercado, o que gera um descarte igualmente crescente e interminável.

A ideia é que, quanto mais a sociedade consome, maior é a produção de mercadorias e, consequentemente, maior a geração de empregos, maior a circulação de dinheiro, maior a arrecadação de impostos, enfim, economia aquecida é um termo alardeado pelos capitalistas. Os recursos naturais são finitos, a exploração do trabalhador deve ter limite, a acumulação de riqueza, apesar de legitimada pela sociedade capitalista, só faz aumentar as desigualdades sociais. (ALVES, 2015, p.75)

Ainda segundo o autor consumir é um direito do consumidor e a produção cria os objetos que correspondem às necessidades desses consumidores, existe uma produção imediatamente análoga ao consumo e que gera a produção a partir do aniquilamento do produto produzido no primeiro consumo. 
O direito consumir cria um véu de fetiche onde a mercadoria estimula o consumo incessante e o ato de consumir torna-se um direito natural para aqueles oriundos dessa sociedade.

O trabalhador vai com o tempo se coisificando e as mercadorias são personificadas. A sociedade contemporânea concede um valor supremo à mercadoria. Através da propaganda cria-se a falsa percepção que o consumo traz a felicidade e faz com que o indivíduo sinta-se integrado à sociedade. Não é preciso ter, apenas aparentar ter. O ser, os valores que outrora foram celebrados foram substituídos pela sensação do ter. (ALVES, 2015, p.87)

O designer, como profissional e uma engrenagem importante desse contexto, tem de assumir uma grande responsabilidade, pensando de maneira mais ampla, passando a desenvolver projetos sustentáveis, ao lado do usuário na construção de uma sociedade que buscar o equilíbrio entre produção e consumo, entre a busca do lucro e o respeito aos limites dos recursos naturais, entre trabalho e lazer, e assim como estabelece Alves (2015), alcançando qualidade de vida em um desenvolvimento sustentável, ainda que alguns busquem esse ideal, muitos estão voltados para a acumulação de riqueza, com o olhar direcionado apenas para o consumo desenfreado, para a o uso desregrado de insumos e matérias primas, para uma geração de resíduos que são insuportáveis dentro do contexto atual mundial. Entretanto o autor esclarece que a indústria e as grandes empresas tem se utilizado do crescimento sustentável apoiado em produção consciente e renovável, adotando medidas que preservam o meio ambiente, garantindo a qualidade de seus produtos e mantendo a produtividade. "E é claro que uma empresa sustentável ou ecologicamente correta faz propaganda disso" (ALVES, 2015, p.78), rapidamente a indústria adaptou-se às novas condições e oscilações do mercado mantendo a imagem de preservação do meio ambiente perante organismos internacionais que regulamentam o mercado e atribuem uma imagem das empresas perante a população. A questão segundo Alves (2015) é se a chamada economia verde ou desenvolvimento sustentável, após décadas de exploração do meio ambiente de forma agressiva e desenfreada, conseguirá reverter ou pelo menos paralisar a degradação ambiental evitando desfigurar ainda mais o restante da biodiversidade do planeta.

Os artifícios do mundo burguês, oriundos da revolução industrial, e a necessidade de atender uma nova classe média consumidora que surgia a rebote da industrialização se revelaram nos produtos que Moles (2001) define pelo conceito de kitsch ${ }^{4}$. Já para Eco (2008) o kitsch está intrínseco nos comportamentos exagerados da sociedade contemporânea e definindo-o como sendo a comunicação intensa que tende à provocação de efeito de consumo. Moles (2001) esclarece que o conceito original, do final do século XIX e início do século XX, tende ainda a persistir na contemporaneidade, onde mesmo nos dia de hoje, os produtos kitsch, são geralmente confeccionados com materiais que nunca se apresentam como são: a madeira que pode ser pintada imitando o mármore (patina, decoupage, etc); os objetos de zinco, bronzeados; as estátuas de bronze, por sua vez, douradas, polímeros e resinas de diferentes texturas imitando os mais diversos materiais. "O Kitsch baseia-se em uma civilização consumidora que produz para consumir e cria para produzir, em um ciclo cultural em que a noção fundamental é a de aceleração" (MOLES 2001, p.2). Os grandes magazines, quando abriram suas portas a partir da segunda metade do século XIX, foram os canais que mais deram vazão aos novos produtos que visavam agradar essa nova classe média consumidora com produtos de baixa qualidade, essa produção é o resultado do excesso de meios em face das necessidades que surgiram.

A insatisfação é gerada quando o sujeito é apresentado a algo que ainda não tem, mas que é mostrado como um consumo que precisa ser feito para se inserir ou manter no estilo de vida escolhido. A falta desse produto é mostrada como uma forma de reprovação enquanto tê-lo é o reconhecimento no meio desejado. Podemos associar à esse conceito de incertezas e crises de identidades a busca do indivíduo em ser sempre uma "mercadoria atraente e desejável" (BAUMAN, 2008).

Wood Jr. (1992) ao descrever a evolução das linhas de montagem de automóveis esclarece que Henry Ford desenhou toda a linha de produção do Ford T com um objetivo muito claro: deveriam ser

\footnotetext{
${ }^{4} \mathrm{O}$ termo kitsch era utilizado para designar o mau gosto artístico e produções consideradas de qualidade inferior. Aparece no vocabulário dos artistas e colecionadores de arte em Munique, em torno de 1860 e 1870, com base em kitschen, atravancar, e verkitschen, trapacear, vender outra coisa no lugar do objeto combinado, o que denota imediatamente o sentido pejorativo que o acompanha desde o nascimento. (MOLES, 2001)
} 
fabricados carros que fossem acessíveis economicamente para seus funcionários, para que eles mesmos pudessem consumir o produto de seu trabalho. O sonho de Henry Ford era democratizar o automóvel, produzi-lo em larga escala e com um custo suficientemente baixo para que todo cidadão pudesse ter acesso a um. Esta visão é essencial para o desenvolvimento da indústria automobilística mundial. Ao desenvolver métodos mais eficazes, com materiais mais baratos e rotinas de produção bem definidas, Ford conseguiu possibilitar a fabricação de carros mais baratos e em larga escala.

Enfocar e administrar as organizações como máquinas significam fixar metas e estabelecer formas de atingi-las; organizar tudo de forma racional, clara e eficiente; detalhar todas as tarefas e, principalmente, controlar, controlar, controlar... Após dois séculos de industrialização e desenvolvimento capitalista, temos estes valores já interiorizados. Quando do seu surgimento, o gerenciamento científico foi visto como solução para todos os problemas. Ainda hoje muitas indústrias, ou mesmo unidades ou departamentos dentro de empresas, encontram na administração científica uma resposta para os seus problemas. Mas isto pressupõe condições ambientais estáveis, produtos com poucas mudanças ao longo do tempo e previsibilidade do fator humano. (WOOD JR. 1992, p.8)

A evolução desse processo de produção serial em outras indústrias automobilísticas ao redor do mundo como a Toyota e a Volvo, a partir de uma maior disponibilidade de matéria prima, aperfeiçoamento das tecnologias, mão de obra mais especializada, além de uma intensa campanha de marketing político, foram os grandes impulsionadores para o consumo também nesse segmento.

\subsection{Consumo Ético como Reflexão}

Para Denis (1998), toda sociedade projeta, em sua cultura material, seus anseios ideológicos e espirituais. Todo designer, como testemunha de seu tempo, não somente projeta uma forma ou um objeto, mas também projeta nas coisas a sociedade em que vive e seus próprios anseios. Canclini (1999) esclarece que o consumo serve também para refletirmos sobre a sociedade que vivemos em dois aspectos: quando os bens de consumo são investigados, sob o ponto de vista antropológico, notase que os objetos construídos por um determinado grupo social dizem muito a respeito de sua cultura; e sobre o ponto de vista arqueológico os objetos são o reflexo de sua época, de sua história.

Bauman (2008) apresenta o conceito de transformação de nossa sociedade com o passar do tempo, partindo da ideia de uma sociedade de produtores, para se tornar uma sociedade de consumo, e como ela é apresentada nos dias de hoje. Na sociedade de produtores as pessoas eram guiadas para o caminho da segurança, conforto, estabilidade, onde o desejo e consequentemente o consumo era direcionado para bens duráveis e que tinham grande visibilidade na sociedade, como joias, carros e casas. Esses bens além de status e conforto traziam a sensação de segurança. A segurança era o item mais valorizado nessa sociedade de produtores onde, quanto mais bens duráveis se adquirissem, mais segurança contra as incertezas do destino se tinha. Nenhum prazer era imediato, usufruir e desfrutar de prazeres era sempre adiado.

Esse desejo era de fato uma matéria-prima bastante conveniente para que fossem construídos os tipos de estratégias de vida e padrões comportamentais indispensáveis para atender à era do "tamanho é poder" e do "grande é lindo": uma era de fábricas e exércitos de massa, de regras obrigatórias e conformidade ás mesmas, assim como de estratégias burocráticas e panópticas de dominação que, em seu esforço para evocar disciplina e subordinação, basearam-se na padronização e rotinização do comportamento individual. (BAUMAN, 2008, p.42).

Ainda segundo Bauman (2008) com a transição de valores, onde o seguro, a prudência o durável parou de ter tanta importância e passamos a querer o imediato, a querer desfrutar dos prazeres naquele momento, nos transportamos para uma sociedade de consumo. Não vemos mais sentido em coisas duráveis já que passamos a valorizar a rapidez, o agora, e passamos a estar sempre em busca de 
satisfazer nossos desejos e anseios em imediato. A vida social e a busca incessante pela felicidade passam a tomar prioridade em nossas vidas.

Naturalmente, a diferença entre viver na nossa sociedade ou na sociedade que imediatamente a antecedeu não é tão radical quanto abandonar um papel e assumir outro. Em nenhum dos seus dois estágios a sociedade moderna pôde passar sem que seus membros produzissem coisas para consumir - e, é claro, membros das duas sociedades consomem. A diferença entre os dois estágios da modernidade é "apenas" de ênfase e prioridades - mas essa mudança de ênfase faz uma enorme diferença em praticamente todos os aspectos da sociedade, da cultura e da vida individual. (BAUMAN, 1998, p. 88)

Para Canevacci (2009) o consumo, a comunicação e a cultura têm uma produção de valores, não só no sentido econômico, mas valores no sentido antropológico. Cavenacci extrapola o conceito de indivíduo dentro da cultura contemporânea, principalmente ao relacioná-lo com o mundo digital. Define a existência de um ser múltiplo como "multivíduo", os vários "eus" existentes em apenas um ser que gera conflitos internos e muitas incertezas.

Então, a cultura e a comunicação digital, que colocam em crise esta perspectiva coletiva, conseguem afirmar o processo conectivo que significa que a individualidade, que prefiro chamar de multivíduo se multiplica, se amplia, explode. Uma multiplicidade de eus no corpo subjetivo. Essa condição múltipla favorece a proliferação dos eus o que acaba por desenvolver outro tipo de identidade, fluida e pluralizada, que coloca, potencialmente em crise, as formas perversas e tradicionais do dualismo. (CAVENACCI, 2009, p. 9)

Bauman (2008) em um exemplo de venda e consumo nos expõe três casos: pessoas a procura de um par em um site de relacionamento, clientes querendo ampliar sua rede de créditos para obter melhores serviços, e potenciais imigrantes em busca de pontuações para serem aceitos no Reino Unido. O que não parece a princípio casos relacionados entre si, se bem analisados observar-se que a forma de promoção e a consequente conquista desses três objetivos acabam sendo a mesma. Três categorias de pessoas, utilizando de todos os recursos, são encorajadas a se expor como a melhor mercadoria possível, aumentando seu valor no mercado, para que possa ser aceita dentro de cada nicho desejado. Essa transformação do ser em mercadoria está ainda mais exposta quando pensamos que em uma sociedade de consumidores todas as pessoas querem ser conhecidas, pois ninguém mais quer ser escondido, ridicularizado e desaprovado. Todos querem destaque, ser notável e aprovado como uma mercadoria desejável.

\subsection{Reflexões}

O indivíduo ideal para uma sociedade de consumo é aquele que jamais está satisfeito com os bens possuídos e está sempre a procura e disposto a consumir mais para suprir essa insatisfação. O consumo de um produto deve, sim, trazer a sensação de satisfação. Sensações que precisam ser imediatas e breves, para que o consumidor logo queira algo novo. Os indivíduos da pós-modernidade vivem em uma sucessão de presentes, onde são satisfeitas as vontades naquele presente e logo surge a insatisfação. Entende-se que a questão do consumo excessivo passou a ser uma questão de responsabilidade cultural. O Design é fundamental neste processo em direção ao futuro sustentável, repensando a forma como estamos produzindo e entregando produtos e serviços, de forma que todos possam viver em abundância sem comprometer o entorno nem o bem estar desta e das futuras gerações. Ainda para Bauman (2008) não existe um ser não consumidor, existe um consumidor falho. $\mathrm{O}$ consumidor ideal deve permanecer com o desejo de consumo sempre aceso e, para que ele nunca apague, é necessário que sempre exista uma grande quantidade de escolhas e possibilidades. "A maneira como a sociedade atual molda seus membros é ditada, primeiro e acima de tudo, pelo dever de desempenhar o papel de consumidor" (BAUMAN, 1999, p. 87). Nesse contexto o designer assume 
uma difícil tarefa de não inibir o consumo prejudicando a indústria, mas atendendo a questões éticas de sobrevivência dos recursos ambientais frente à demanda excessiva.

Segundo o relatório Frota por Município de dezembro de 2019, do DENATRAN ${ }^{5}$, Departamento Nacional de Trânsito, a frota de carros da cidade de São Paulo era de quase 8,6 milhões de automóveis. Ainda segundo os dados do DENATRAN, em 2018, 270 mil carros (740 por dia) foram acrescentados à frota da cidade, um crescimento que em poucos anos poderá tornar a circulação no trânsito da cidade completamente inviável. Essas informações levam a questionar sobre o momento em que desenho de produção industrial estará sendo pensado em prol do usuário e da sustentabilidade.

Em outro seguimento o mais recente Relatório apresentando o Panorama dos Resíduos Sólidos no Brasil 2018/2019 ${ }^{6}$, única publicação do país sobre gestão de resíduos sólidos que indica tendências e desafios do setor, indica que em 2018 , houve um aumento de $0,82 \%$ na produção de resíduos sólidos no Brasil em relação ao ano anterior, um total de 216.629 toneladas diárias. Índice bem superior à taxa de crescimento populacional no país no período, que foi de $0,40 \%$. O relatório também indica que a geração per capita de resíduos sólidos teve elevação de $0,39 \%$, significando que, em média, cada brasileiro gerou mais de 1 quilo de resíduo diariamente. Entretanto a política de reciclagem de resíduos sólidos ainda é bastante incipiente no nosso país, dos 79 milhões de toneladas de resíduos sólidos produzidos no Brasil em 2018 apenas 391.526 toneladas teve como destino a reciclagem, o que representa um percentual de menos de $0,5 \%$.

O sistema de produção capitalista é baseado na produção e no consumo, o designer dentro deste âmbito passa a ter uma responsabilidade ética de sustentabilidade que acaba por se tornar uma premissa para a sua profissão. Entende-se que o designer tem uma formação multidisciplinar abrangente e sistêmica, e que essa percepção proporciona ao profissional atuar em todas as fases do processo industrial. Löbach (2001) afirma que é preciso estudar a posição do designer não somente dentro da indústria, mas também em sua formação nas escolas de design, relatando que esse profissional não pode atuar exclusivamente na indústria, pois é necessário ter o pensamento voltado a questões de processo e estética, onde a preocupação com o meio ambiente e a sustentabilidade se une ao do design em um projeto para a sociedade.

Em cada projeto devemos questionar em primeiro lugar a importância que ele terá para a sociedade, se o resultado do processo de planejamento e de configuração é sensato, se há aspectos negativos a considerar. Não deverão ser consideradas somente as vantagens econômicas e sim os possíveis efeitos sobre a comunidade. (LÖBACH, 2001, p.22)

Por possuir um caráter mediador e uma relação com inovações socioculturais e tecnológicas o profissional da área de design adquire competências amplas e transdisciplinares. Segundo Alves "A empresa possui como lógica a obtenção de lucros, mesmo a custa da exploração de trabalhadores e degradação dos recursos naturais" (ALVES, 2015, p. 78). Mas o designer dentro de sistema tem um compromisso ético pelo desenvolvimento de projetos que atenda as demandas de mercado e que também visem minimizar os impactos ambientais dos mesmos, pensando em todo ciclo de vida do projeto. Esses profissionais podem refletir sobre os valores e o estilo de vida que estão estimulando e divulgando, sobre as aspirações e desejos que estão gerando no consumidor para, de forma mais abrangente, inclusiva e criativa, repensar os velhos estilos e criar novos conceitos.

$\mathrm{O}$ designer não pode mais pensar seu trabalho de forma desassociada a questões ambientais e morais. É uma questão de vida ou morte que o designer repense o caráter ambiental de sua produção entendo que a minimização do impacto ambiental também pode gerar ganhos a economia em longo prazo. O profissional de design na contemporaneidade tem como premissa criar soluções que atendam especificamente as necessidades do usuário bem como as do meio ambiente no que se refere aos processos produtivos sustentáveis.

\footnotetext{
${ }^{5}$ Disponivel em: < https://www.gov.br/infraestrutura/pt-br/assuntos/transito/conteudo-denatran/frota-deveiculos-2019> Acesso em: 08 agosto 2020

${ }^{6}$ Disponivel em: < https://abrelpe.org.br/panorama/ > Acesso em: 08 agosto 2020
} 


\section{A Reflection on Design of Paper and Ethics in Consumption.}

Abstract: This article aims to reflect on consumption and consumerism, and design of the role and its responsibilities, as a possible partner in the search for new sustainable and ethical models. Analyzing the practice of consumption through the study of primary and secondary needs of the consumer, but also the role of industry and its relationship with advertising and marketing.

Keywords: ethics; consumption; design; marketing; needs

\section{Referências bibliográficas}

ALVES, Fábio Carlos Rodrigues.. In: ALVES, Fábio Carlos Rodrigues. A contextualização do binômio produção e consumo à luz dos conceitos da cultura e da ideologia. São Paulo: Editora Edgard Blücher, 2015, p. 75-96.

AMORIM, Patrícia. CAVALCANTI, Virginia. Design, produção e consumo no contemporâneo: notas para uma investigação, in Anais do $9^{\circ}$ Congresso Brasileiro de Pesquisa e Desenvolvimento em Design. São Paulo, 2010. Disponível em: <https://pt.scribd.com/document/337320667/Anais-9-Ped2010> Acesso em: 08/08/2020.

BAUMAN, Zygmunt. Globalização: as consequências humanas. Rio de Janeiro: Jorge Zahar Editor, $1999,145 \mathrm{p}$.

BAUMAN, Zygmunt. Vida para consumo: A transformação das pessoas em mercadoria. Rio de Janeiro: Jorge Zahar Editor, 2008, 200 p.

BAXTER, M. Projeto de produto: guia prático para o design de novos produtos. São Paulo: Edgard Blücher, 1998, p. 344.

CANCLINI, Néstor García. Consumidores e cidadãos: Conflitos multiculturais da globalização. 4. ed. Rio de Janeiro: UFRJ, 1999, 228 p.

CAVENATTI, Massimo. Comunicação entre corpos e metrópoles. Revista Signos do Consumo V.1, N.1. Departamento de Relações Públicas, Propaganda e Turismo da ECA - USP, 2009. P. 8-20. Disponível em: <http://www.revistas.usp.br/signosdoconsumo/article/view/42762> Acesso em: 08/08/2020.

MANZINI, EZio; VEZZOLI, Carlo. O desenvolvimento de produtos sustentáveis: os requisitos ambientais dos produtos industriais. São Paulo: Ediusp, 2005, 368 p.

DENIS, Rafael Cardoso. Design, cultura material e o fetichismo dos objetos. Revista Arcos Volume I - Número único. Programa de Pós-Graduação em Design / ESDI. Rio de Janeiro, 1998. Disponível em: < https://almodotblog.files.wordpress.com/2017/04/design-cultura-material-efetichismo-dos-objetos.pdf> Acesso em: 08/08/2020.

ECO, Umberto. Apocalípticos e Integrados. 6. ed. São Paulo: Perspectiva, 2008, 392 p.

FLUSSER, Vilém. 0 mundo codificado: por uma filosofia do design e da comunicação. São Paulo: Cosac Naif, 2013. 224 p.

LÖBACH, Bernd. Design Industrial: bases para a configuração dos produtos industriais. São Paulo: Edgard Blücher, 2001. 208 p.

MODERNO, Maria Cláudia Simões. Mecanismos psicológicos da publicidade e do marketing. Millenium - Revista do Instituto Politécnico de Viseu, n. ${ }^{2}$ 20, 2000. Disponível em: <http://www.ipv.pt/millenium/Millenium_20.htm> Acesso em: 08/08/2020.

MOLES, Abraham. 0 kitsch: a arte da felicidade. São Paulo: Editora Perspectiva, 2001, 231 p. 
NORMAN, Donald A. Design emocional: por que adoramos ou detestamos os objetos do dia-a-dia. $1^{\text {a }}$ edição. Rio de Janeiro: Rocco, 2008. 323 p.

OLÍVIO, Dennis Henrique Vicário; CARVALHO, J. L. ; BIANCARDI, L. ; GALLO, Z. A ética do consumo. Revista eletrônica Scientia FAER, Ano 2, Volume 2. Faculdade de Olímpia / UNIESP, São Paulo: 2010, p. 16-27. Disponivel em: <http://uniesp.edu.br/sites/olimpia/revista.php?id_revista=36> Acesso em: 08/08/2020.

TAVARES, Mauro Calixta. URDAN, André Torres. SHIGAKI, Helena Belintani. Transferência de significados entre consumidores, personagens e marca: proposição de um novo modelo. Revista Brasileira de Marketing. São Paulo, 2014. Disponível em:

<http://www.revistabrasileiramarketing.org/ojs-2.2.4/index.php/remark/issue/view/138/showToc> Acesso em: 08/08/2020.

WOOD JR, Thomaz. Fordismo, Toyotismo e Volvismo: os caminhos da indústria em busca do tempo perdido. Revista de Administração de Empresas / EAESP / FGV, São Paulo, 1992, p. 6-18. 